\title{
Genetic Depletion of Amylin/Calcitonin Receptors Improves Memory and Learning in Transgenic Alzheimer's Disease Mouse Models
}

\author{
Aarti Patel ${ }^{1} \cdot$ Ryoichi Kimura $^{1,2} \cdot$ Wen Fu $^{1} \cdot$ Rania Soudy $^{1,3} \cdot$ David MacTavish $^{1} \cdot$ David Westaway $^{1,4,5} \cdot$ Jing Yang $^{1,5}$. \\ Rachel A. Davey ${ }^{6}$ Jeffrey D. Zajac ${ }^{6}$. Jack H. Jhamandas ${ }^{1}$ (D)
}

Received: 11 May 2021 / Accepted: 8 July 2021 / Published online: 27 July 2021

(C) The Author(s) 2021

\begin{abstract}
Based upon its interactions with amyloid $\beta$ peptide $(A \beta)$, the amylin receptor, a class B G protein-coupled receptor (GPCR), is a potential modulator of Alzheimer's disease (AD) pathogenesis. However, past pharmacological approaches have failed to resolve whether activation or blockade of this receptor would have greater therapeutic benefit. To address this issue, we generated compound mice expressing a human amyloid precursor protein gene with familial AD mutations in combination with deficiency of amylin receptors produced by hemizygosity for the critical calcitonin receptor subunit of this heterodimeric GPCR. These compound transgenic AD mice demonstrated attenuated responses to human amylin- and A $\beta$-induced depression of hippocampal long-term potentiation (LTP) in keeping with the genetic depletion of amylin receptors. Both the LTP responses and spatial memory (as measured with Morris water maze) in these mice were improved compared to AD mouse controls and, importantly, a reduction in both the amyloid plaque burden and markers of neuroinflammation was observed. Our data support the notion of further development of antagonists of the amylin receptor as AD-modifying therapies.
\end{abstract}

Keywords Amylin $\cdot$ Amylin receptor $\cdot$ Calcitonin receptor $\cdot$ Alzheimer's disease $\cdot$ Amyloid- $\beta$ protein $\cdot$ Long-term potentiation $\cdot$ Hippocampus $\cdot$ Spatial memory

\section{Introduction}

Aarti Patel, Ryoichi Kimura, and Wen Fu contributed equally to this work.

Jack H. Jhamandas

jack.jhamandas@ualberta.ca

1 Department of Medicine (Neurology), Neuroscience and Mental Health Institute, University of Alberta, Edmonton, AB T6G 2S2, Canada

2 Center for Liberal Arts and Sciences, Sanyo-Onoda City University, Yamaguchi 756-0884, Japan

3 Faculty of Pharmacy, Cairo University, Giza, Egypt

4 Department of Biochemistry, University of Alberta, Edmonton, AB T6G 2H7, Canada

5 Centre for Prions and Protein Folding Diseases, University of Alberta, Edmonton, AB T6G 2M8, Canada

6 Department of Medicine, University of Melbourne, Austin HealthHeidelberg, VIC 3074, Australia
A defining pathological feature of Alzheimer's disease (AD) is the presence of soluble oligomers of amyloid beta (A $\beta$ ) that aggregate into extracellular fibrillary deposits known as amyloid $\beta$-plaques [1]. Although the role of the brain $\mathrm{A} \beta$ in $\mathrm{AD}$ is not completely resolved, available evidence indicates that it may initiate and/or contribute to the process of neurodegeneration [2, 3]. Neuronal dysfunction, synaptic disruption, neuroinflammation, and vasculopathy are key perturbations of AD pathology and each is linked to the presence of $\mathrm{A} \beta$ in the brain $[1,3]$. $\mathrm{A} \beta$ protein has been shown to interact with a number of $G$ protein-coupled receptors (GPCRs) to modulate major cognitive and pathological features of $\mathrm{AD}$ and has thus become attractive therapeutic targets for the development of disease-modifying treatments for AD.

We have shown that human amylin, a 37-amino acid peptide identified in pancreas of diabetics, causes neurotoxicity in a manner very similar to $A \beta$, and that the effects of the human amylin and $A \beta$ on neurons appear to be expressed via the same receptor, the amylin receptor, a class B G protein-coupled receptor [4]. Pharmacological 
studies using the amylin receptor antagonist, AC253, have shown beneficial effects on synaptic function, spatial memory and learning, and neuroinflammation in transgenic mouse models of AD [5-7]. However, other studies have reported that the systemic administration of human amylin or pramlintide, a synthetic non-amyloidogenic analog of amylin, is capable of improving deficits in spatial memory $[8,9]$. Thus, to address these contradictory findings arising from the pharmacological evidence, we generated a line of transgenic ( $\mathrm{Tg}$ ) AD mice expressing a genetically induced deficit in amylin/calcitonin receptors, but carrying the full amyloid protein precursor (APP) gene and resultant overexpression of $A \beta$. If the amylin receptor is indeed a mediator of deleterious effects of $A \beta$, one would expect a significant reduction and/or delay in the development of age-dependent pathology and memory-related deficits in the $\mathrm{AD}$ mice bearing a reduced complement of amylin receptors compared to $\mathrm{AD}$ mice.

Dimerization of the calcitonin receptor (CTR) with one of the three receptor activity-modifying proteins (RAMP1, RAMP2, or RAMP3) yields subtypes of amylin receptors (AMY1-3) that bind amylin with varying affinities $[10,11]$. As such, CTR is a critical component for the functionality of the amylin receptor, i.e., without CTR, there is no functional amylin receptor even if RAMPs are present. We have previously shown that in cell cultures of human fetal neurons, siRNA downregulation of CTR blunts $A \beta$-induced cell death [4]. Thus, to extend these in vitro findings, we sought to genetically deplete CTR receptors in the transgenic AD mice. Since homozygosity for CTR null alleles is embryonic lethal, we sought to assess the impact of hemizygosity for the CTR locus. We thus obtained stocks of CTR mice with one inactivated CTR allele (HetCTR) [12]. These HetCTR mice, producing $50 \%$ of the amylin receptor complement of wild-type (WT) mice, were crossed with two strains of transgenic AD mice. We used TgCRND8 and 5xFAD lines of mice, both of which express APP695 and develop A $\beta$-related neuropathology consisting of large numbers of diffuse plaque amyloid deposits in tandem with a progressive deterioration of spatial memory [13, 14]. Crossing such hemizygous null CTR (HetCTR) mice with TgCRND8 or $5 \times$ FAD mice produces HetCTR + TgCRND8 or 5xFAD compound $\mathrm{Tg}$ mouse offspring, which have $50 \%$ depletion of amylin receptors but will continue to overexpress $A \beta$ deriving from the separate APP695 transgene array. Thus, the compound mice could be used to test whether or not a constitutive genetic depletion of amylin receptors alters the AD-related pathology and memory-related deficits that follow from expression of FAD alleles of human APP695. More generally, this approach allows a critical assessment of some contradictory pharmacological findings and the potential benefits of modulating the AMY/CTR axis in clinical dementia settings.

\section{Materials and Methods}

All experiments were conducted in compliance with the guidelines set by the Canadian Council for Animal Care and with the approval of the Human Research Ethics Board and Animal Care Use Committee (Biomedical Sciences) at the University of Alberta (Protocol AUP00000268).

\section{Chemical and Reagents}

All commercially available chemicals were of analytical grade and used without further purification. Oligomeric $\mathrm{A} \beta_{1-42}$ was prepared according to published protocol [15]. Briefly, $\mathrm{A} \beta_{1-42}$ (rPeptide) was dissolved to $1 \mathrm{mM}$ in $100 \%$ hexafluoroisopropanol, hexafluoroisopropanol was removed under vacuum, and the peptide was stored at $-20{ }^{\circ} \mathrm{C}$. For oligomeric conditions, the peptide was first re-suspended in DMSO to $5 \mathrm{mM}$, then water added to bring it to a final concentration of $1 \mathrm{mM}$, and the peptide incubated at $4{ }^{\circ} \mathrm{C}$ for $24 \mathrm{~h}$. The hAmylin (AnaSpec Inc.) was dissolved to $1 \mathrm{mM}$ in water and kept at $-80^{\circ} \mathrm{C}$. Aliquots of $\mathrm{A} \beta$ and hAmylin were further diluted to final application concentration with cell culture medium.

\section{Animal Models}

Mice were maintained in standard laboratory housing conditions $\left(20 \pm 1{ }^{\circ} \mathrm{C} ; 70 \% \pm 10 \%\right.$ humidity; $12: 12 \mathrm{~h}$ light/dark cycle). Access to standard rodent chow and water was available ad libitum.

For behavior and histological studies, we used non-Tg (C57BL/6xC3H background) and TgCRND8 mice (human APP695 transgene array incorporating Swedish K670M/ N671L and Indiana V717F mutations superimposed upon a C57BL6xC3H genetic background), which have been described previously to exhibit $\mathrm{A} \beta$ plaques and cognitive deficits from 3 months of age onwards [13]; these mice originating from the University of Toronto are being deposited at the Jackson Lab, Bar Harbor, ME (JAX \# 020,661). $5 x F A D$ amyloid precursor protein (APP)/presenilin 1 (PS1) double transgenic mice with five familial AD mutations [14] mouse breeding stocks were obtained from the Jackson Laboratory (JAX \#006,554) and correspond to a C57BL6xSJL hybrid background. Additionally, heterozygous CTR (HetCTR) age-matched mice (C57BL/6 J background) with a $50 \%$ depletion of CTR expression were obtained using breeding pairs provided from Drs. RA Davey and JD Zajac (University of Melbourne, Australia), these being obtained as C57/BL6 congenic stock [15]. Crosses of HetCTR and 
heterozygous Tg-positive mice (5xFAD or TgCRND8) were set to obtain compound heterozygotes (i.e., hemizygous for a functional CTR locus and heterozygous for carrying the APP-expressing transgene array). Both male and female mice were used in our study.

Early and late stage male and female AD mice with and without CTR depletion and their WT littermate controls were evaluated at approximately 4 and $8-12$ months of age, respectively, and described henceforth as 4 and 8 months of age. In both cases, the animals were stratified by age to maintain equivalent age distributions between WT and transgenic experimental groups.

\section{Genotyping Mouse Lines}

$T g C R N D 8$ mice were genotyped using PCR primers in the human APP coding region and the hamster PrP 3'-untranslated region, 5'.TGTCCAAGATGCAGCAGAACGGCT ACGAAAA.3', and 5'.AGAAATGAAGAAACGCCAAGC GCCGTGACT.3'. PCR with Taq polymerase (Invitrogen) was performed with a $94{ }^{\circ} \mathrm{C}$ melt step (180 s) followed by 35 cycles using a $94{ }^{\circ} \mathrm{C}$ melt temperature $(20 \mathrm{~s})$, hybridization at $68{ }^{\circ} \mathrm{C}(20 \mathrm{~s})$, and extension at $72{ }^{\circ} \mathrm{C}(90 \mathrm{~s})$.

$5 x F A D$ mice were genotyped with APP and presenilin 1 primer sets.

APP 5'.AGGACTGACCACTCGACCA.3' transgene forward and 5'.CGGGGGTCTAGTTCTGCA T.3' transgene reverse, with 5'.CTAGGCCACAGAATT GAAAGA TCT.3' internal positive control forward and 5'.GTAGGTGGA AATTCTAGCATCATC.3' internal positive control reverse primer. The APP amplicon is $377 \mathrm{bp}$, and the control amplicon 324 bp. Cycles were 35 cycles using a $94{ }^{\circ} \mathrm{C}$ melt temperature $(30 \mathrm{~s})$, hybridization at $51^{\circ} \mathrm{C}(60 \mathrm{~s})$, and extension at $72{ }^{\circ} \mathrm{C}(60 \mathrm{~s})$.

PSEN1 5'.AATAGA GAACGGCAGGAGCA. 3' transgene forward and 5'.GCCATGAGGGCACTAATC AT.3' transgene reverse with internal control primers as per APP. PSEN1 amplicon $=608$ bp. 35 cycles using a $94{ }^{\circ} \mathrm{C}$ annealing temperature ( $30 \mathrm{~s})$, hybridization at $54{ }^{\circ} \mathrm{C}(60 \mathrm{~s})$, and extension at $72{ }^{\circ} \mathrm{C}(60 \mathrm{~s})$.

$C T R$-the presence of the deleted allele of the mouse CTR locus was identified by PCR using with a 5' exon 11 primer 5'.GCTGGCTGAGTGCAGAAA.3' and a 3' primer CTRR8 5'.CGGTGAGTAATGAATGAAGTGAA.3'. Using Elongase Taq polymerase (Invitrogen 10,480-028), PCR was performed for 35 cycles using a $94{ }^{\circ} \mathrm{C}$ annealing temperature (30 s), hybridization at $58^{\circ} \mathrm{C}(30 \mathrm{~s})$, and extension at $68^{\circ} \mathrm{C}(90 \mathrm{~s})$.

$P d e 6 b$ - mice entered for behavioral testing were also genotyped for $r d l$ to exclude any homozygotes with retinal degeneration caused by the proviral element insertion into the Pde6b gene. Primers were 5'.AAGCTAGCTGCA GTAACGCCATTT.3' mutant allele and 5.ACCTGCATG
TGAACCCAGTATTCTATC.3' wild-type allele and using 5'.CTACAGCCCCTCTCCAAGGTTTATAG.3' as a common primer. The mutant allele amplicon is $560 \mathrm{bp}$ and the wild-type allele is $240 \mathrm{bp}$. PCR with Taq polymerase (Invitrogen) was performed with a $94{ }^{\circ} \mathrm{C}$ melt step (300 s) followed by 35 cycles using a $94{ }^{\circ} \mathrm{C}$ melt temperature $(30 \mathrm{~s})$, hybridization at $65^{\circ} \mathrm{C}(20 \mathrm{~s})$, and extension at $72{ }^{\circ} \mathrm{C}(90 \mathrm{~s})$.

All primers were used at $0.4 \mu \mathrm{M}$ of each final concentration and PCR reactions were performed in $25 \mu \mathrm{l}$ volumes with $200 \mathrm{ng}$ of genomic DNA. After polymerization cycles, reactions were incubated at $120 \mathrm{~s}$ at $72{ }^{\circ} \mathrm{C}$ for chain completion before electrophoretic analysis.

\section{Behavioral Testing}

\section{Morris Water Maze (MWM)}

The MWM apparatus (Harvard Apparatus) consisted of 2-m circular blue plastic pool filled with water $\left(24-25^{\circ} \mathrm{C}\right)$, which was rendered opaque by the addition of nontoxic white paint. An escape platform (20 cm in diameter) was submerged $0.5 \mathrm{~cm}$ under the water level. Dark posters, different in shape (one per wall), provided distant landmarks. The behavior of a mouse was recorded by a video camera connected to a video tracking system (HVS Image 2100, HVS Image, Buckingham, UK). The pool was surrounded by a white curtain, and a mouse was released facing the wall at points $(\mathrm{N}, \mathrm{E}, \mathrm{S}, \mathrm{W})$ which were chosen semi-randomly. The mice were trained for 3 days ( 4 trials per day) to find a submerged platform located in the center of the NE quadrant of the pool (target quadrant, TQ). The trial ended when a mouse found and climbed onto the platform within $120 \mathrm{~s}$. If the mouse failed to find the platform, it was guided to the platform by an experimenter. After a 10-s post-trial time on the platform, the mouse was placed in a holding cage to dry. Mice were tested with inter-trial interval of $50 \mathrm{~min}$. Memory was evaluated in probe trial, administered on day 4 as the first trial of the day. During probe trial, the platform was removed from the pool. Memory for the platform location was expressed as the percent of time spent in TQ.

\section{Slice Preparation and Electrophysiology}

Brains were quickly removed from mice following decapitation and placed in a cold artificial cerebral spinal fluid (aCSF) on a vibratome chamber, and transverse sections cut through the hippocampus. The aCSF contained (in millimolar) $124 \mathrm{NaCl}, 3 \mathrm{KCl}, 2.4 \mathrm{CaCl}_{2}, 2 \mathrm{MgCl}_{2}, 1.25 \mathrm{NaH}_{2} \mathrm{PO}_{4}, 26$ $\mathrm{NaHCO}_{3}$, and $10 \mathrm{D}$-glucose and was equilibrated with $95 \%$ $\mathrm{O}_{2}$ and $5 \% \mathrm{CO}_{2}$. Hippocampal slices (400- $\mu \mathrm{m}$ thick) were maintained in aCSF-filled holding chamber at $28{ }^{\circ} \mathrm{C}$ for at least $1 \mathrm{~h}$ and individually transferred to the submerged glass bottom recording chamber, which was constantly perfused 
with aCSF $(2 \mathrm{ml} / \mathrm{min})$ at $30{ }^{\circ} \mathrm{C}$. Field excitatory postsynaptic potential (fEPSP) was recorded with a metallic (Pt/Ir) electrode (FHC, Bowdoin, ME) from the stratum radiatum layer of cornu ammonis 1 (CA1) region of the hippocampus area, and the Schaffer collateral afferents were stimulated with $100-\mu$ s test pulses via a bipolar cluster electrode (FHC; Fig. 1). To evaluate basal synaptic transmission, we applied different stimulation strengths (50 to $275 \mu \mathrm{A}$ in increments of $25 \mu \mathrm{A}$ ) and plotted fEPSP slopes versus amplitudes of the presynaptic fiber volleys in order to compare the slope of input/output (I/O) curves of fEPSP. In the following experiments, stimulus current was adjusted so that fEPSP stabilized at $40-50 \%$ of maximum. To test paired-pulse facilitation, we measured the percentage increase in the slope of fEPSP relative to the first one with different inter-pulse intervals $(20-500 \mathrm{~ms})$. For long-term potentiation (LTP) experiments, test pulses were delivered to Schaffer collaterals once every $30 \mathrm{~s}$. LTP was induced by 3 times-theta-burst stimulation (3-TBS) protocol (each burst consisted of four pulses at $100 \mathrm{~Hz}$ with a 200-ms inter-burst interval). Before 3-TBS or drug application, the responses were monitored for at least $10 \mathrm{~min}$ to ensure a stable baseline of fEPSP. To determine whether the magnitude of LTP differed significantly between groups, average responses during the last 20-min block of recordings (40-60 min after TBS) were compared. All drugs and chemicals were applied directly to the slice via bath perfusion, which allowed for a complete exchange of the perfusate in less than a minute and a half.

\section{Thioflavin S Amyloid Plaque Staining}

After completion of treatments, all mice were sacrificed with an overdose of isoflurane anesthetic, perfused transcardially with normal saline using a syringe infusion pump (Harvard Apparatus) at $5 \mathrm{~min} / \mathrm{min}$ rate for $5 \mathrm{~min}$. For brain vessel tracing, mice were perfused for another 5 min with Evans Blue (Sigma) solution (1\%) in PBS. The brains were dissected, right hemisphere was frozen for biochemical analysis (western blot), and the left hemisphere was fixed with $4 \%$ paraformaldehyde-PBS for $24 \mathrm{~h}$ at $4{ }^{\circ} \mathrm{C}$. These brain tissues were further processed with modified CLARITY protocol (http://www.chunglabresources.com/ clarity/). Briefly, the fixed brain tissue was transferred to hydrogel monomer solution (4\% polyacrylamide in PBS) at $4{ }^{\circ} \mathrm{C}$ for $24 \mathrm{~h}$, and subsequently to a 24 -well plate, merged in fresh hydrogel solution and the tissue brought to $37{ }^{\circ} \mathrm{C}$ till formation of the gel. The sagittal slices $(400 \mu \mathrm{m})$ were cut on an HR2 Slicer (Sigman Electronic, Germany) and cleared with $8 \%$ SDS in PBS for $24 \mathrm{~h}$, followed by $0.3 \%$ Triton X-100 in PBS for $24 \mathrm{~h}$. A modified thioflavin S staining was used for detecting $A \beta$ plaques. Briefly, the brain sections were rinsed with distilled water, incubated with thioflavin S $(0.0125 \%$ in $50 \%$ ethanol) solution for
5 min, and then washed with 50\% ethanol and water. The brain slices were further incubated with DAPI (Invitrogen) in PBS solution for $5 \mathrm{~min}$. The stained clear slices were mounted on a glass slide using Dow Corning high vacuum grease that surrounds to cylinder shapes of a thickness slightly more than the thickness of slice. Images were captured using fluorescence microscopy (Axioplan-2, Carl Zeiss Ltd). Amyloid plaque size and area were analyzed with Image $\mathbf{J}$ software.

\section{Immunofluorescence for Mouse Brain Slices}

The cleared brain slices were first blocked in 2\% BSA $+10 \%$ goat serum for $4 \mathrm{~h}$. The brain slices were then exposed to primary antibodies for $24 \mathrm{~h}$ at $4{ }^{\circ} \mathrm{C}$, followed by washing with PBS and exposure to secondary antibodies for $4 \mathrm{~h}$.

\section{Human Endothelial Cell Culture and Stain}

Human dermal microvascular endothelial (HMEC-1, ATCC ${ }^{\circledR}$ CRL-3243 ${ }^{\mathrm{TM}}$ ) cells were grown in MCDB131 medium (Life Technologies) with 10\% FBS. For amyloid plaque formation, HMEC- 1 cells were plated at 2000 cells per well in an 8-well chamber culture slide incubated with $1 \mu \mathrm{M} \mathrm{A} \beta_{1-42}$ for $24 \mathrm{~h}$. Cells were washed with room temperature PBS three times $(3 \times)$, fixed with $4 \%$ paraformaldehyde-PBS for $10 \mathrm{~min}$, and washed $3 \times$ with DPBS. Cells were incubated for $1 \mathrm{~h}$ in blocking solution (1\% BSA containing 5\% goat serum). Primary antibodies (6E10, CTR, RAMP3) were applied $2 \mathrm{~h}$ at room temperature. Cells were washed $3 \times$ in PBS, incubated with secondary antibodies (Alexa Fluor) with DAPI for $1 \mathrm{~h}$ at room temperature, and washed $3 \times$ for 10 min in PBS. Secondary antibodies were used at 1:500 dilution (all Alexa Fluor antibodies from Thermo Fisher). Fluorescent imaging was performed on an Axioplan 2 fluorescence microscopy (Carl Zeiss Ltd).

\section{Western Blot}

Frozen brain tissues or cultured cells were homogenized in cold RIPA buffer with protease inhibitors and proteins were quantified with BCA assay (BioRad, Mississauga, ON, Canada). Proteins were loaded at $50 \mu \mathrm{g}$ per lane on a $12 \%$ polyacrylamide gel. Proteins were transferred to nitrocellulose membrane and then blocked with Odyssey blocking buffer. Blots were further incubated with primary antibodies overnight at $4{ }^{\circ} \mathrm{C}$ on a shaker. IRDye $800 \mathrm{CW}$ goat anti-rabbit and IRDye $680 \mathrm{CW}$ goat anti-mouse (Li-Cor, 1:10,000) were used as secondary antibodies. Blots were imaged using Odyssey image system (Li-Cor). 
Fig. 1 Amylin and amyloid beta $(\mathrm{A} \beta)$ modulation of hippocampal long-term potentiation (LTP) in CTR depleted mice. a Western blot shows CTR protein expression in HetCTR mouse brain which is reduced to approximately $50 \%$ level of that for WT control littermate mice. Histograms (top) and representative western blots (below) show levels of CTR and the loading control $\beta$-actin following serial dilutions of whole brain protein from HetCTR and WT mice ( $n=3$ each group). b Right and middle panels showing input-output (I/O) curves that do not demonstrate significant change in basal synaptic transmission between HetCTR ( $n=6$, one slice per mouse) and WT mice $(n=5$, one slice per mouse). Left panel: paired-pulse facilitation across different interstimulus intervals (20$500 \mathrm{~ms})$ in HetCTR $(n=6$ one slice per mouse) and WT mice ( $n=5$, one slice per mouse). c, d LTP traces and scatter plots show that there was no difference between WT and HetCTR mice. In WT mice, applications of hAmylin $(50 \mathrm{nM})$ or $\mathrm{A} \beta_{1-42}$ $(50 \mathrm{nM})$ induced a reduction of LTP. However, hemizygosity for the CTR locus significantly reduced this hAmylin $(50 \mathrm{nM})$ or $\mathrm{A} \beta_{1-42}(50 \mathrm{nM})$-induced LTP inhibition $(n=8-9$, one slice per mouse for each group, ${ }^{*} p<0.05, * * p<0.01$; one-way ANOVA followed Tukey's test). All results shown are mean \pm SEM
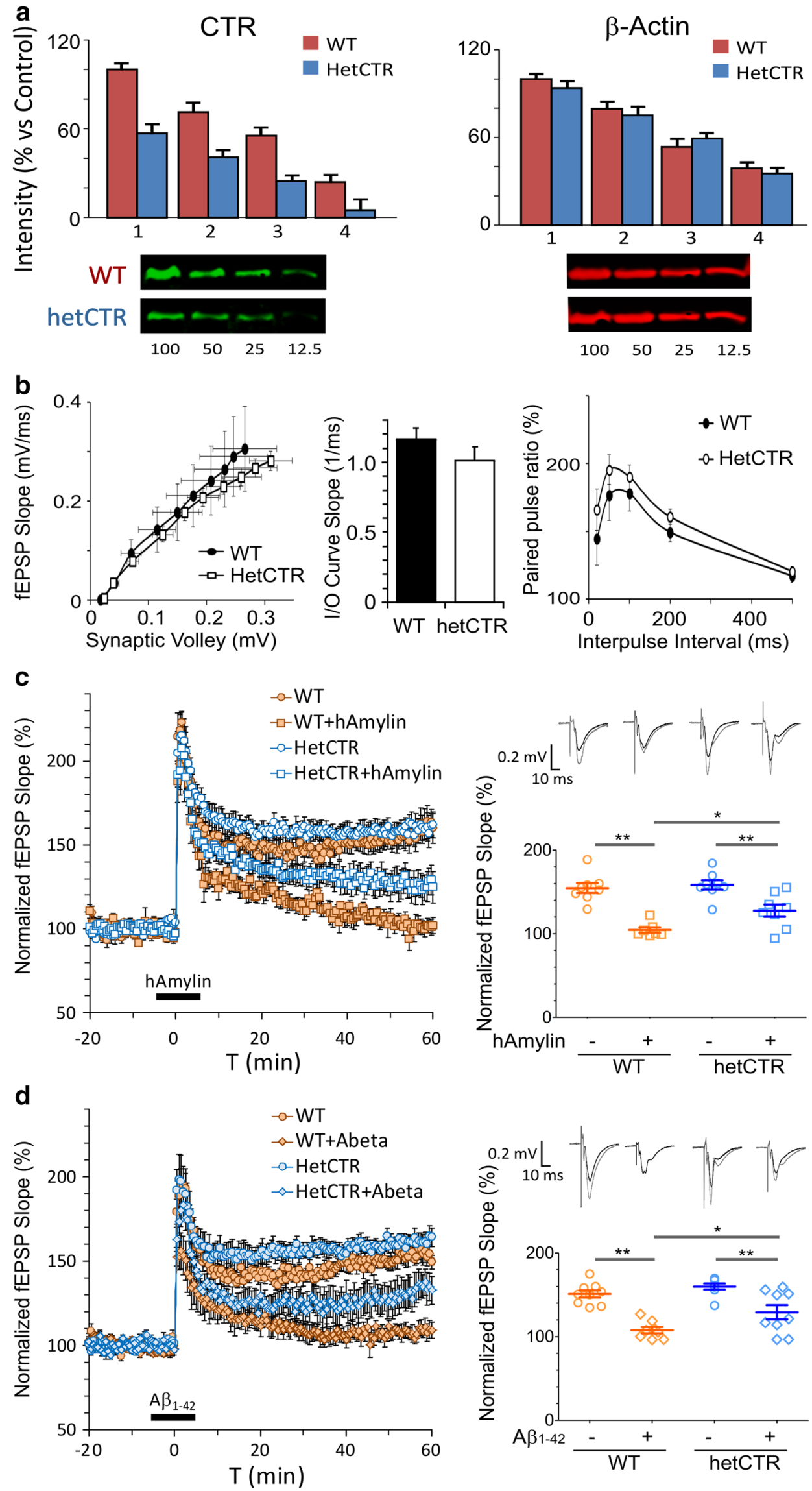


\section{Experimental Design and Statistical Analysis}

All experiments in the current study were performed on age-matched, male and female 5XFAD, TgCRND8, 5XFAD + HetCTR, TgCRND8 + HetCTR, wild-type (WT), and HetCTR mice. We used independent groups of animals to conduct the electrophysiological experiments and behavioral tests. For electrophysiological experiments, one hippocampal brain slice per mouse was used for each group ( $n=8-9$ mice). Seven to 12 mice per group were used for behavioral tests and investigator was blinded to the groups for the behavioral assessments. Experimental details specific for behavioral testing are included in the "Behavioral Testing" section above. For all biochemical and histology experiments, a minimum of 5 animals per experiment were used. Then the number per group for each individual set of experiments is stated in each figure legend. Unpaired, twotailed $t$ tests were used for comparison between two groups, with $p \leq 0.05$ considered significant (for LTP and biochemi$\mathrm{cal} /$ histological data). For all comparisons involving multiple variables, one-way ANOVA was performed followed by post hoc test for multiple comparisons using $p \leq 0.05$ for significance (for LTP and MWM data). Bar graphs have been included to show the appropriate statistical information (mean \pm SEM). All statistical analyses were performed using Prism (GraphPad Prism 5, San Diego, CA).

\section{Results}

\section{Synaptic Plasticity in the Hippocampal Slices from HetCTR (AMY/CTR Depleted) Mice}

Depletion of CTR in HetCTR mice was first confirmed with western blot analysis (Fig. 1a). In HetCTR mice, CTR protein expression is reduced compared to control WT mice following serial dilutions. We next conducted a systematic evaluation of changes in hippocampal synaptic functions in HetCTR mice at 3-4 months of age. In hippocampal slices from $\leq 4$-month-old HetCTR mice, input/output (I/O) curves of fEPSPs at Schaffer collateral-CA1 synapses in response to different stimulation strengths were not significantly different from those of WT controls (Fig. 1b). Thus, the basal synaptic transmission as assessed by the average slope of $\mathrm{I} / \mathrm{O}$ curves was not significantly different in WT and HetCTR mice at 4 months of age. We also tested paired-pulse facilitation, which represents a short-term form of synaptic plasticity reflecting presynaptic release probability of the neurotransmitter. Paired-pulse facilitation was indistinguishable between HetCTR mice and WT controls at 4 months of age (Fig. 1b). Therefore, short-lived presynaptic plasticity was normal in HetCTR mice.
Human Amylin and A $\beta$ Actions on Hippocampal LTP in HetCTR Mice

No difference in LTP at hippocampal Schaffer collateralCA1 synapses was identified between HetCTR and WT controls at 4 months of age (Fig. 1c and d). However, exposure of the hippocampal slices from WT mice to either hAmylin $(50 \mathrm{nM})$ or soluble oligomeric $\mathrm{A} \beta_{1-42}(50 \mathrm{nM})$ significantly depressed the LTP induced by application of 3-TBS protocol at the CA1 region $(p<0.01)$. Similarly, in HetCTR mice, hAmylin $(50 \mathrm{nM})$ or soluble oligomeric $\mathrm{A} \beta_{1-42}(50 \mathrm{nM})$ significantly depressed the LTP $(p<0.01)$. Applications of hAmylin or $\mathrm{A} \beta_{1-42}$ induced a significantly lesser depression of LTP in HetCTR versus WT mice $(p<0.05)$. In all experiments, there were $n=8-9$ slices for each group with one slice per mouse.

\section{Effects of AMY/CTR Knock Down in TgCRND8 Mice on Hippocampal Long-Term Potentiation}

A cross-breeding scheme for HetCTR and TgCRND8 mice (Fig. 2a) yielded compound Tg mice (HetCTR + TgCRND8) at the expected 25\% frequency. Hemizygosity for the AMY/ CTR locus did not alter body weight or blood glucose levels across four groups of age-matched mice (Suppl. Figure 1). We compared the LTP responses in 8 to 12 month-old HetCTR + TgCRND8 compound mice to those obtained from WT, HetCTR and TgCRND8 mice (Suppl. Figure 2). We also examined the LTP responses obtained from each set of mice in the presence of the amylin receptor, AC253.

A comparison of the normalized slope of fEPSP during 40-60 min after induction between the four groups revealed that LTP at hippocampal CA1 synapses was markedly reduced in TgCRND8 mice compared to that observed in age-matched WT and HetCTR littermate mice $(p<0.01$, Fig. 2b). However, in the HetCTR + TgCRND8 mice, the LTP deficit observed was partially restored to the levels closer to those observed in age-matched WT or HetCTR mice $(p<0.05)$. Together, these results indicate that impairment of hippocampal LTP in TgCRND8 mice was partially rescued by $50 \%$ depletion of AMY/CTR receptor genes.

We have previously shown that LTP levels at hippocampal Schaffer collateral-CA1 synapses in TgCRND8 mice can be improved in the presence of the peptidergic amylin receptor antagonist, AC253 ( $\mathrm{NH}_{2}$-LGRLSQELHRLQTYPRTNTGSNTY-COOH) [5]. Pre-application of AC253 (250 nM) to hippocampal slices for $5 \mathrm{~min}$ before and after 3-TBS did not affect basal synaptic transmission or the LTP during 40-60 min after its induction in either WT or HetCTR control mice. LTP levels in HetCTR + TgCRND8 mice were improved compared to the reduced LTP that is observed for TgCRND8 mice. Application of the amylin receptor antagonist, AC253, further 
a
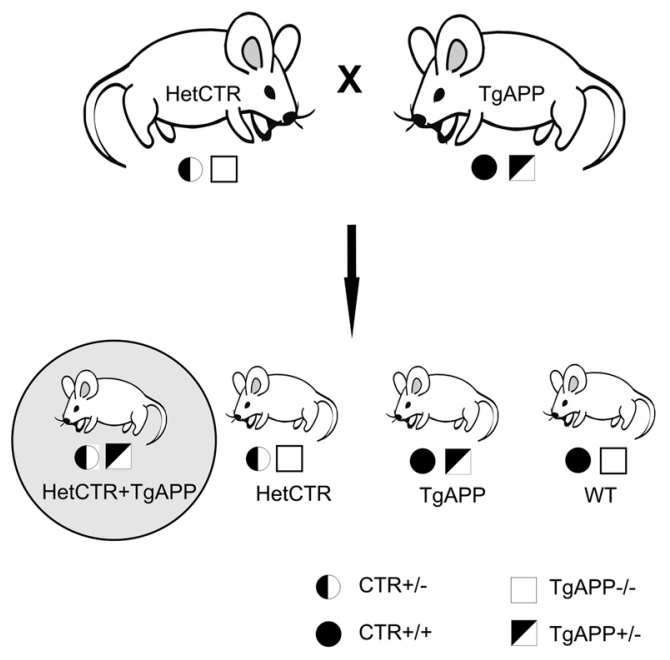

b

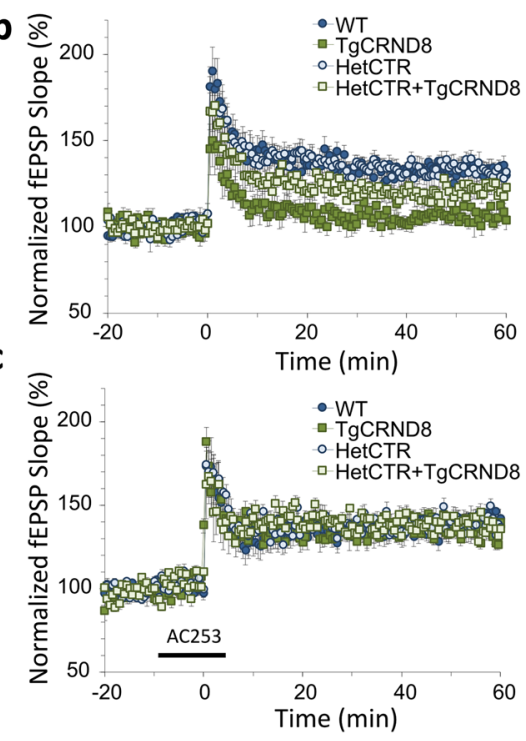

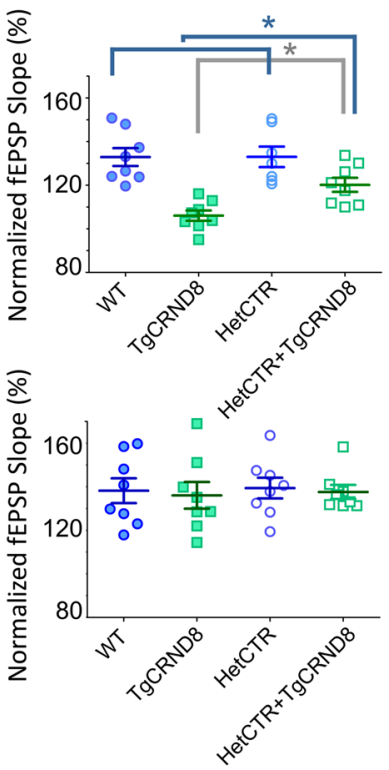
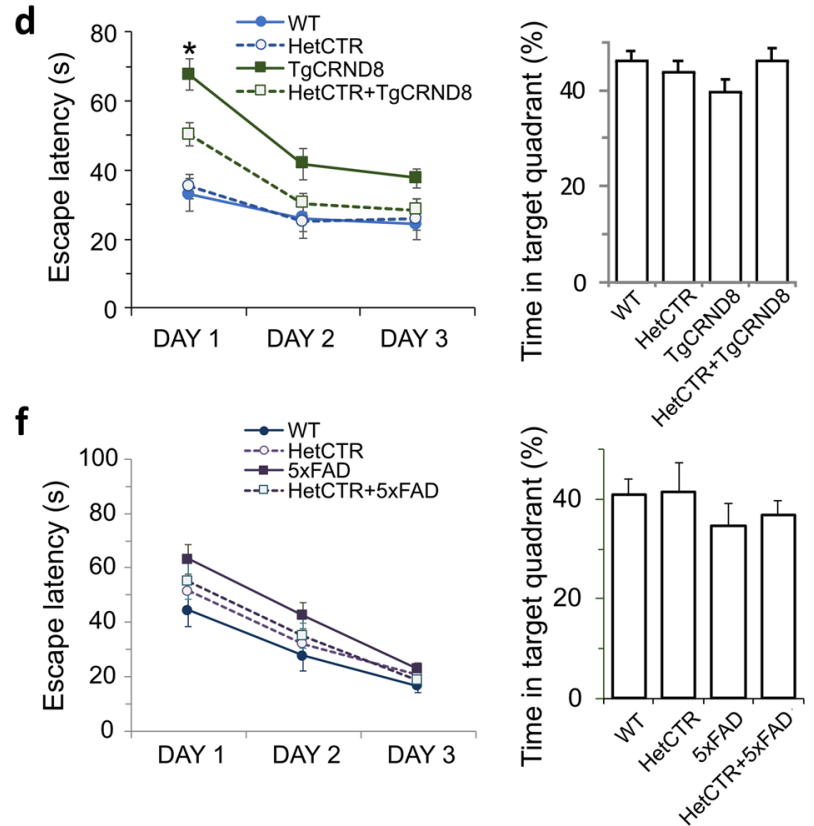

Fig. 2 AMY/CTR depletion improves cognitive function in two mouse models of AD. a Schematic for generating AD mice hemizygous for the AMY/CTR locus. Two different mouse models expressing human APP (TgCRND8 or 5xFAD) were used for generation of AMY/CTR compound $\mathrm{Tg} /$ hemizygous mice. In the schematic shown here, TgAPP refers to either TgCRND8 or 5XFAD strain of mice. b LTP traces (left) and scatter plots (right) show that there is a significant LTP reduction in TgCRND8 mice compared to WT mice; depletion of AMY/CTR receptor in TgCRND8 mice significantly improves LTP (HetCTR + TgCRND8 vs Tg CRND8; $n=8$ for each group, one slice per mouse). No differences between WT ( $n=8$, one slice per mouse) and HetCTR mice ( $n=7$, one slice per mouse) were observed. ${ }^{*} p<0.05$, $* * p<0.01$; one-way ANOVA followed Tukey's test. c Application of AC253 (250 nM), an AMY receptor antagonist, reverses the LTP reductions in both the HetCTR + TgCRND8 and the TgCRND8 mice ( $n=8$ mice for each of the four groups, one slice per mouse). d, e Data from Morris water maze (MWM) and probe tests
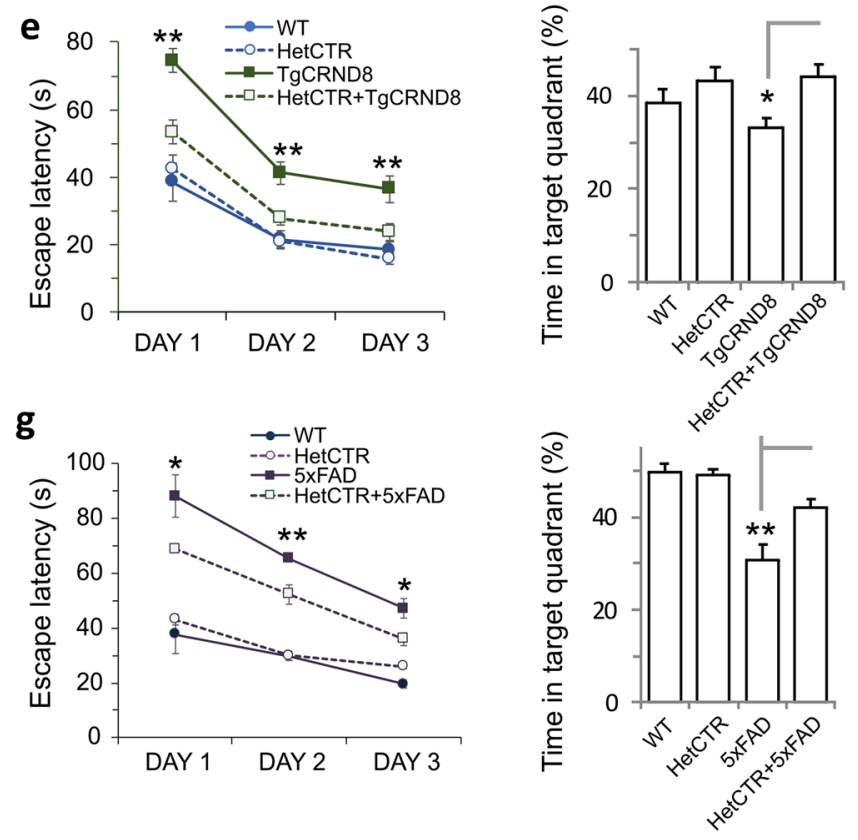

for WT ( $n=8$ mice), HetCTR ( $n=9$ mice), TgCRND8 ( $n=9$ mice), and HetCTR + TgCRND8 ( $n=12$ mice) groups of mice $(\mathbf{d})$ at $6 \mathrm{~m}$ (early cognitive function impairment for $\mathrm{AD}$ mice) and (e) at $9 \mathrm{~m}$ (significant cognitive impairment) of age (e). At 6 months of age, no statistically significant differences in MWM escape latencies or quadrant preference are observed among the four groups. However, at 9 months of age, there is a significant improvement in escape latencies and quadrant preference in 9-month-old HetCTR + TgCRND8 mice compared to their age-matched TgCRND8 littermates. f, $\mathbf{g}$ Data from MWM and probe test from WT ( $n=7$ mice), HetCTR $(n=9$ mice), 5xFAD ( $n=9$ mice), and HetCTR $+5 x$ FAD $(n=10$ mice) groups of mice (f) at $3 \mathrm{~m}$ (early cognitive function impairment for $\mathrm{AD}$ mice) and (g) at $8 \mathrm{~m}$ (significant cognitive impairment) of age. Similar age-dependent improvement in escape latencies and quadrant preference is seen for HetCTR + 5XFAD mice compared to age-matched 5XFAD mice. For experimental data shown in $\mathbf{b}-\mathbf{g}$, ${ }^{*} p<0.05, * * p<0.01$; one-way ANOVA followed Tukey's test 
$a$
$\frac{0}{9}$
$\frac{9}{4}$
등
음

Tg-CRND8

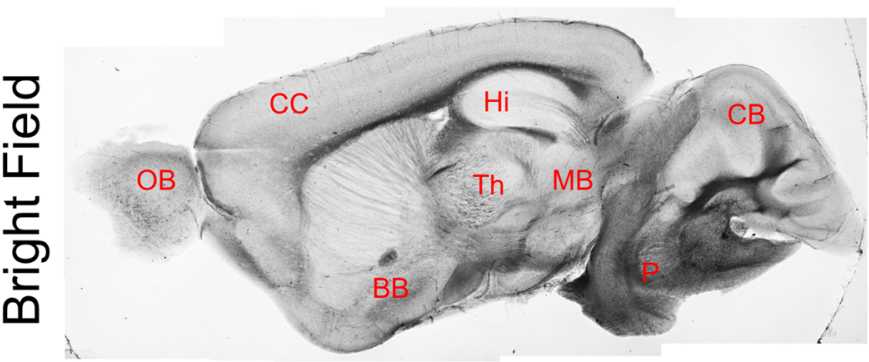

HetCTR+Tg-CRND8
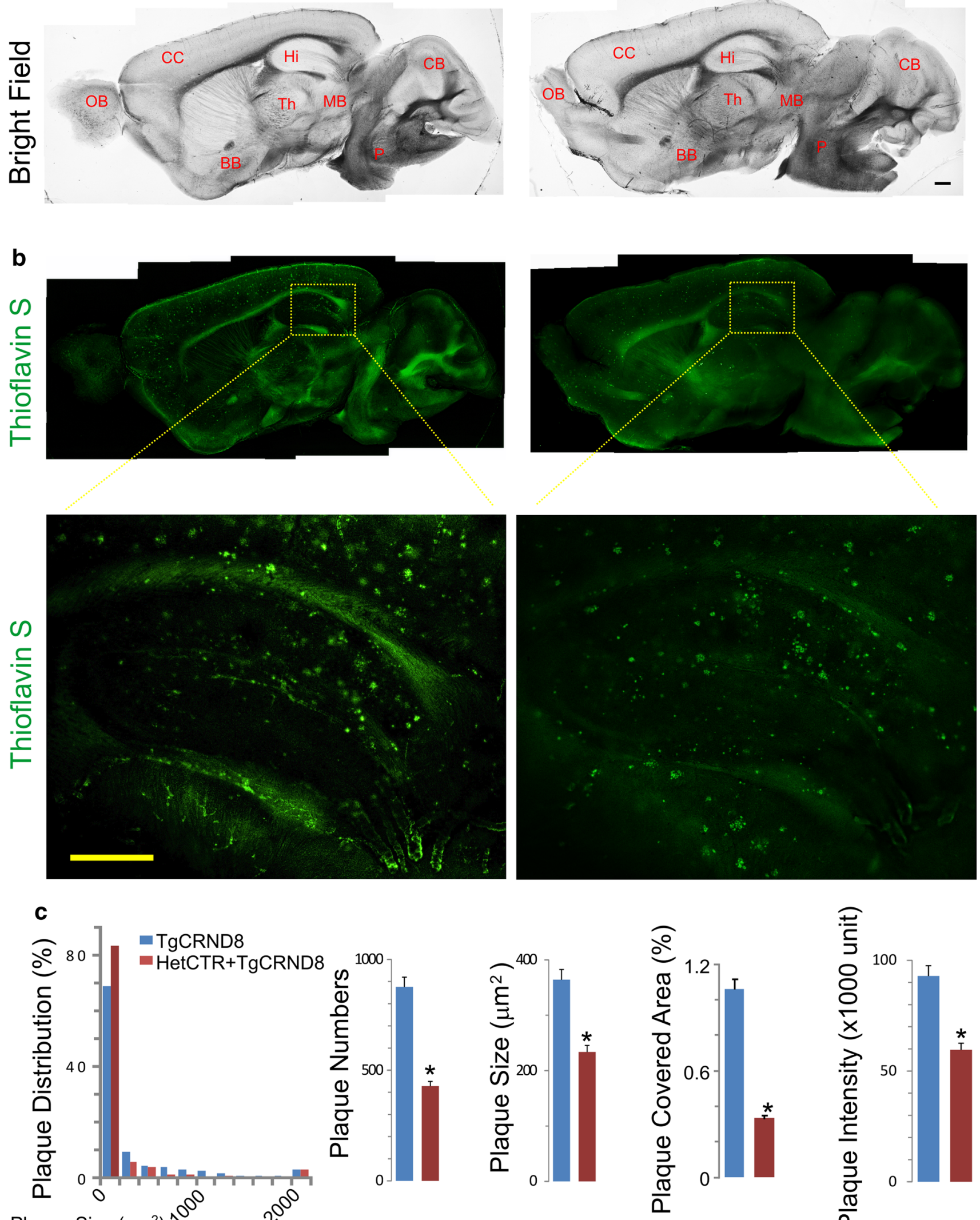

Plaque Size $\left(\mu \mathrm{m}^{2}\right) \wedge^{10^{\circ}} \quad 2^{\circ}$
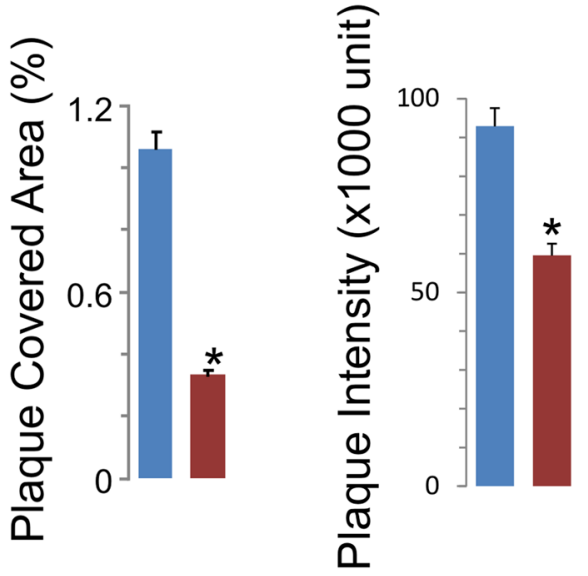
4Fig. 3 AMY/CTR depletion reduced amyloid pathology in AD mice. a Bright field sagittal sections from 8-month-old TgCRND8 and HetCTR + TgCRND8 mice. Abbreviations: OB, olfactory bulb; CC, cerebral cortex; Hi, hippocampus; $\mathrm{BB}$, basal forebrain; Th, thalamus; $\mathrm{MB}$, midbrain; $\mathrm{CB}$, cerebellum; $\mathrm{P}$, pons. b Brain sections stained for thioflavin $\mathrm{S}$, showing the presence of amyloid plaques in an 8-monthold HetCTR+TgCRND8 mice compared to TgCRND8 mouse. Boxed areas in these sections are shown at higher magnification in the lower panels and show a reduction in amyloid plaques within the hippocampal region of HetCTR + TgCRND8 compared to TgCRND8 mice. c Quantification of plaque numbers, plaque sizes, plaque covered area, and plaque fluorescent intensity in the hippocampal region of TgCRND8 and HetCTR + TgCRND8 mice. Data from $n=5$ mice in each group: ${ }^{*} p<0.05$; $t$ test: two sample assuming unequal variances. All results shown are mean \pm SEM. Scale bar in lower panel of $\mathbf{b}=500 \mu \mathrm{m}$

elevated the LTP recorded from HetCTR + TgCRND8 mice to levels that were comparable to age-matched WT littermate mice (Fig. 2c). In all above experiments, there were $n=8-9$ slices for each group with one slice per mouse.

\section{Spatial Memory in AD Mouse Models with AMY/CTR Knock Down}

In order to determine whether the AMY/CTR knock down by $50 \%$ can prevent or delay spatial learning and memory deficits in $\mathrm{AD}$ mice, we used two different aforementioned transgenic mouse models, namely TgCRND8 and 5xFAD mice.

In TgCRND8 mouse model of early-onset AD, we used Morris water maze (MWM) as a behavioral test for spatial memory at two different time points, at 6 months and 9 months of age. At the age of 6 months, there was no difference seen in the escape latency to locate the hidden platform between WT and HetCTR mice (Fig. 2d). TgCRND8 mice demonstrated a significant impairment in performing the same task when compared to WT and HetCTR control mice $(p<0.001)$ However, the performance of HetCTR + TgCRND8 compound mice was superior to that of age-matched TgCRND8 mice $(p<0.05)$. During the probe trial, no differences in total exploration time spent in quadrant containing the target platform were observed among the four experimental mice groups, indicating no significant impairment in memory retention across the groups at 6 months of age (Fig. 2d). At 9 months of age, the difference in MWM performance of HetCTR + TgCRND8 mice versus TgCRND8 mice was greater with the latencies to locate the hidden platform significantly longer for the latter group across all days of testing $(p<0.01)$. On the other hand, there was no significant difference in performance between TgCRND8-HetCTR mice and WT or HetCTR mice. During the probe trial, there was, at this time point, a significant increase in total exploration time spent in the target platform quadrant for the HetCTR + TgCRND8 compared to TgCRND8 mice ( $p<0.05$, Fig. $2 \mathrm{e})$, indicating improved memory retention in AMY/CTR depleted TgCRND8 AD mice.

In a similar manner, we used MWM as a test of spatial memory in $5 \mathrm{xFAD}$ mice at 3 and 8 months of age. At the age of 3 months, there was no significant difference seen in the escape latency to locate the hidden platform between four experimental mice groups (Fig. 2f). However, at the age of 8 months, the latency to locate the hidden platform for $5 \times$ FAD mice was significantly longer than that for HetCTR +5 XFAD $(p<0.01)$ and either WT or HetCTR control mice $(p<0.001)$ (Fig. 2f). Additionally, during the probe trial, there was significant increase in total exploration time spent in the target platform-containing quadrant for WT, HetCTR control mice $(p<0.001)$ or the HetCTR $+5 \mathrm{xFAD}$ mice $(p<0.01)$ compared to $5 \mathrm{xFAD}$ mice (Fig. 2g). HetCTR + 5xFAD mice demonstrated an increase time in target platform quadrant compared to $5 \mathrm{xFAD}$ mice (Fig. 2g) indicative of improved memory retention in AMY/ CTR depleted 5xFAD mice. In all above experiments, there were $n=7-12$ for each group as detailed for each genotype in the figure legend.

\section{Amyloid Pathology in TgCRND8 AD Mice with AMY/ CTR Deficiency}

At the conclusion of our behavioral experiments on AMY/ CTR depleted $\mathrm{AD}$ mice, we sought to also examine aspects of AD pathology in these transgenic mice. Thioflavin $\mathrm{S}$ staining was used to assess the distribution and morphology of amyloid plaques in brains sections along the sagittal plane at the midline. We observed that the number of amyloid plaques in the hippocampus of HetCTR + TgCRND8 mice was significantly decreased as compared to TgCRND8 mice (Fig. 3a-c); for the plaque size, the average area occupied by the plaques and the plaque intensity were quantified and also found to be reduced in the hippocampus (Fig. $3 \mathrm{c} ; n=5$ each group, $p<0.05$ ).

\section{APP and Other Molecular Markers in 5XFAD Mice with AMY/CTR Knock Down}

$\beta$ - and $\gamma$-secretase enzymes are two key elements of the amyloidogenic pathway for APP processing that is associated with the production of $A \beta$. We therefore investigated whether APP processing could also be affected in 5XFAD strain of AD mice with reduced AMY/CTR expression and to this end measured total APP, full-length APP, $\beta$-secretase 1 (BACE1), and soluble oligomeric fraction of $A \beta 42$ in lysates obtained from hippocampal and cortical tissue from 5XFAD and HetCTR +5 XFAD mice ( $n=5$ for each group). Protein levels of total APP, full-length APP, BACE1, and soluble oligomeric $A \beta$ in the brains of HetCTR + 5XFAD 

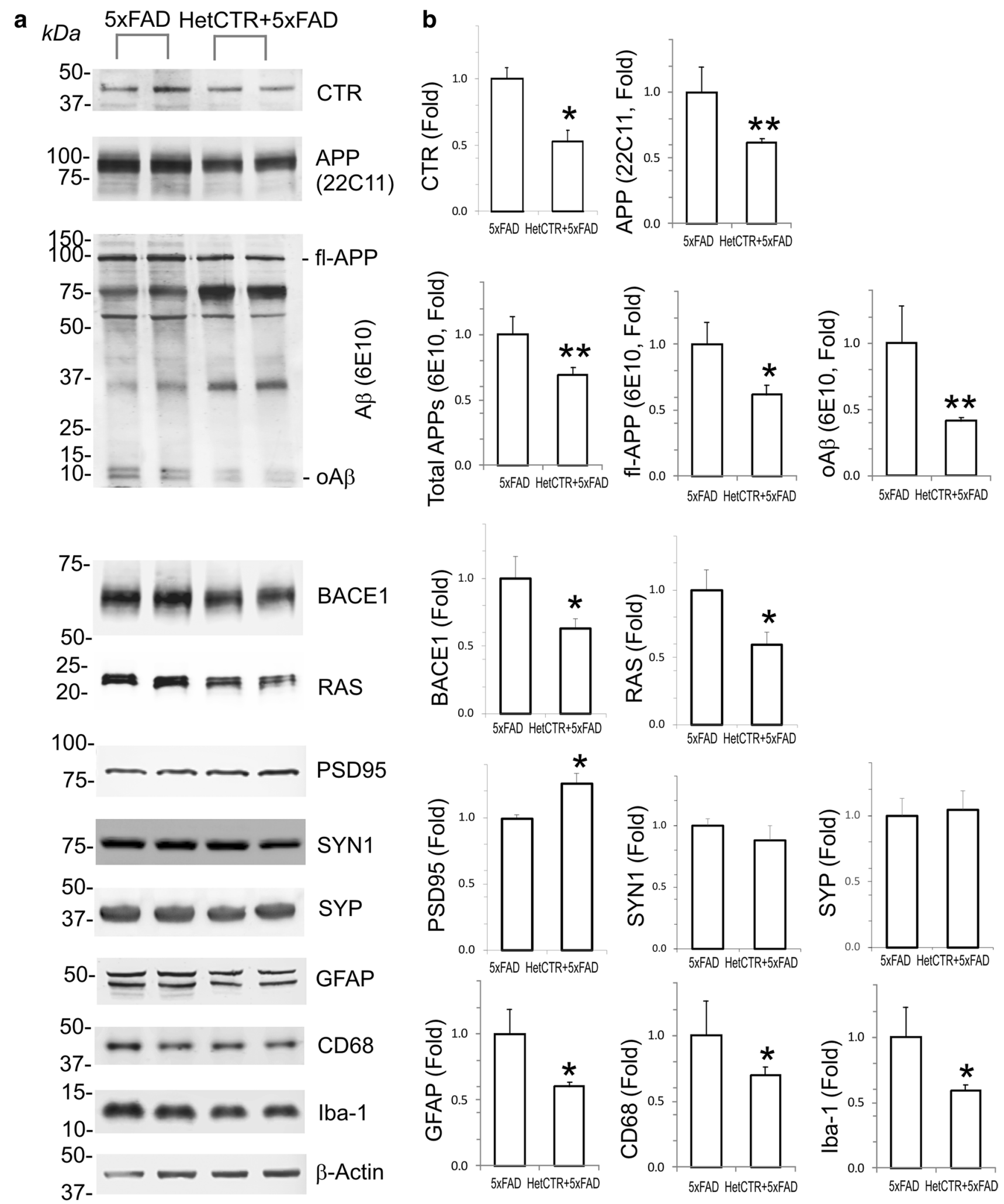

mice were significantly reduced in comparison to those from 5XFAD mice (Fig. 4a, b; Suppl. Figure 3; $p<0.05$ ).

No changes in either synapsin 1 or synaptophysin (presynaptic markers) were observed between
HetCTR + 5XFAD mice and 5XFAD mice that is consistent with the paired-pulse electrophysiological data showing no presynaptic plasticity. However, PSD95 (postsynaptic marker) levels in HetCTR + 5XFAD mice were 
4Fig. 4 Pathological markers for $\mathrm{AD}$ are attenuated in 5xFAD $\mathrm{AD}$ mice compared to $\mathrm{AD}$ mice hemizygous for the AMY/CTR locus. a Western blots from two sets of mice each for $5 \mathrm{xFAD}$ and HetCTR + 5xFAD showing calcitonin receptor (CTR), amyloid precursor protein (APP, total and full length), oligomeric amyloid beta (oA $\beta), \beta$-secretase 1 (BACE1), RAS, PSD95, synapsin 1 (SYN1), synaptophysin (SYP), Iba-1, CD68, GFAP, and $\beta$-actin (loading control). b Histograms of data showing quantification of western blots from $5 x F A D / 5 x F A D-H e t C T R$ brain tissues. Hemizygosity for the AMY/CTR locus in 5XFAD mice (HetCTR + 5xFAD) in addition to demonstrating depletion of CTR revealed reduced APP, including total APP, full-length APP, APP-22C11, oA $\beta$, BACE1, and RAS. Postsynaptic marker (PSD95) was increased in HetCTR + 5XFAD mice compared to $5 \mathrm{XFAD}$ mice but no change observed in presynaptic markers SYN1 and SYP. In HetCTR + 5xFAD mice, a reduction of reactive astrocytes (GFAP) and activated microglia (Iba-1 and CD68) was also observed. Data from $n=5$ mice for each group; $* p<0.05$, $* * p<0.01, t$ test: two sample assuming unequal variances. All results shown are mean \pm SEM

increased compared to 5XFAD mice. Downstream signaling protein, RAS, a GTPase that is linked to amylin receptor activation, is reduced in HetCTR + 5XFAD mice compared to 5XFAD mice (Fig. 4b; Suppl. Figure 3; $p<0.05$ ).

We also examined microglial (CD68 and Iba-1) and astrocytic (GFAP) markers in brain lysates from the two strains of transgenic mice. Protein levels of CD68, Iba1 , and GFAP as determined by western blot analysis and quantified using Image $J$ analysis also were significantly lower in HetCTR + 5XFAD mice compared to 5XFAD mice (Fig. 4b; Suppl. Figure 3; $p<0.05$ ).

\section{Involvement of AMY/CTR Receptor in Vascular Amyloid Pathology}

Thioflavin S staining method was used to assess the distribution and morphology of amyloid plaques within cerebral blood vessels from the cortex sectioned along the sagittal plane. Amyloid pathology was readily visualized within the cerebral vasculature of TgCRND8 mice, but appeared reduced in HetCTR + TgCRND8 mice (Fig. 5a, $n=5$ for each group). The number of amyloid plaques, plaque size, and their intensity were quantified and were observed to be reduced within the blood vessels from HetCTR + TgCRND8 mice compared to those from TgCRND8 mice (Fig. $5 b ; p<0.05$ ). In addition to the abundant vascular amyloid pathology (Fig. 5c), the presence of AMY/CTR receptor expression within the walls of the cerebral blood vessels of TgCRND8 mice was visualized using CTR and RAMP3 antibodies (Fig. 5d). AMY/ CTR receptor was present on endothelial cells (HMEC-1) and $\mathrm{A} \beta$ plaque-like deposits were observed on HMEC-1 cells expressing CTR and RAMP3 heterodimeric components of the amylin receptor (Fig. 5e).

\section{Discussion}

\section{Amylin Receptor Action and AD Pathogenesis}

The amylin receptor, a class B GPCR, is viewed as a plausible therapeutic target for AD based upon observations that modulation of this receptor by either synthetic amylin analogs or amylin antagonists confers improvement in spatial memory and learning [6-8, 16, 17]. In order to resolve the dichotomy of whether it is activation or blockade of the amylin receptor that holds promise as a therapeutic strategy, we used a genetic approach consisting of a deletion within one copy of an endogenous chromosomal locus. In this study, we show for the first time that a partial depletion of a critical heterodimeric component of the amylin receptor, CTR, superimposed on expression of human APP695 with two familial AD mutations, results in improvement of memory-related responses in the resulting compound $\mathrm{Tg}$ mice. In hippocampal brain slices from these HetCTR mice, the impairment of hippocampal LTP induced by exposure to human amylin or $\mathrm{A} \beta$ is ameliorated by approximately $50 \%$ compared to that in wild-type (WT) littermate controls. The attenuation of $\mathrm{A} \beta$ or human amylin-evoked LTP responses thus proved proportionate to the reduction of CTR gene copy number (and hence the amylin receptor protein) in HetCTR mice. Additionally, the reduction of LTP responses normally observed in human APP-expressing TgCRND8 mice is significantly improved in HetCTR + TgCRND8 compound mice. HetCTR + 5XFAD mice also demonstrate an increase in the postsynaptic marker, PSD95, compared to 5XFAD mice. These electrophysiological observations suggest that a reduction in the amylin receptor leads to a significant improvement in an electrophysiological response that is widely accepted as a cellular surrogate of memory. Furthermore, in the HetCTR + TgCRND8 and HetCTR $+5 x$ FAD mice, we observed a significant improvement in spatial memory compared to the two strains of AD mice expressing mutant FAD forms of human APP695 in the context of a full complement of CTR expression (i.e., in animals that were homozygous WT for the CTR locus).

Deposition and fibrillation of human $A \beta$ in both the TgCRND8 and 5xFAD mice is an age-dependent process that is important in AD pathogenesis and matched by progressive deficits in memory performance and cellular surrogates of memory $[9,13,14,18,19]$. The effects of a substantial reduction in a putative target for the deleterious actions of the $A \beta$, namely AMY/CTR, would be expected to become more apparent with time. Indeed, the observed improvement in spatial memory in HetCTR + TgCRND8 or HetCTR5 + FAD mice compared to TgCRND8 or 

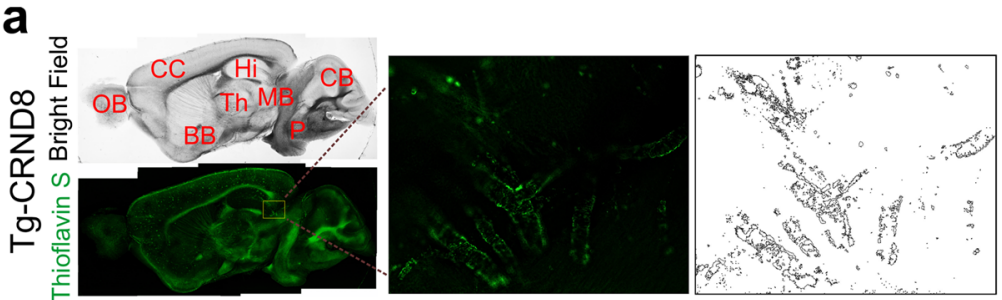

\section{C}
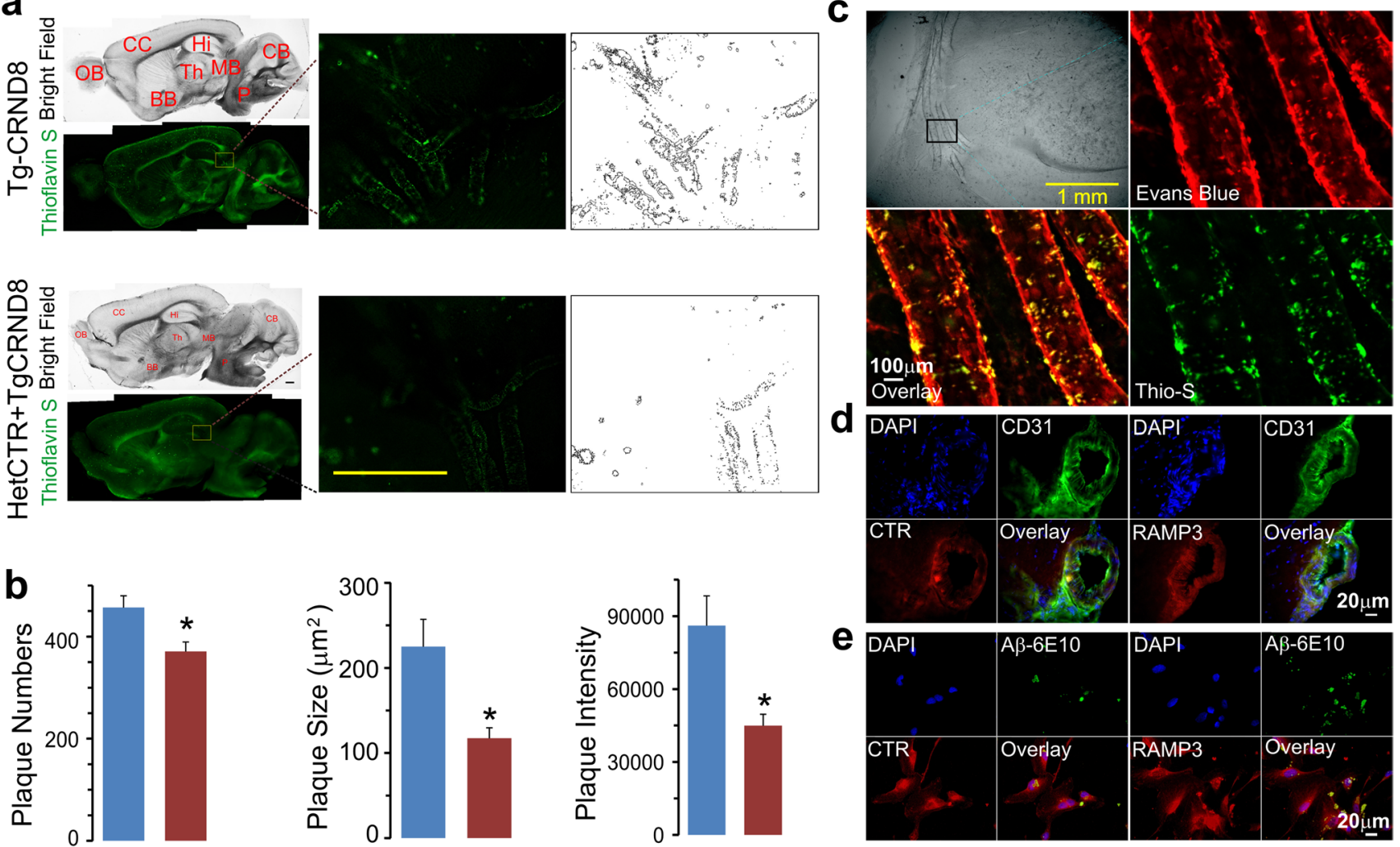

Fig. 5 Vascular amyloid pathology in AMY/CTR depleted AD mice. a Left, bright field and thioflavin $\mathrm{S}$ stained sagittal brain sections from TgCRND8 and HetCTR + TgCRND8 mice. Right, higher magnification of sections showing amyloid deposition within the cerebral vasculature (left) and Image $\mathbf{J}$ generated profiles of amyloid-positive blood vessels (right). Hemizygosity for AMY/CTR results in a reduction in vascular amyloid pathology in AD mice. Scale bar $=500 \mu \mathrm{m}$. b Histograms depict quantification of amyloid plaque number, size, and intensity using Image $\mathbf{J}$ analysis of the thioflavin S-positive blood vessels. Data are from 5 mice in each group; ${ }^{*} p<0.05, t$ test: two sample assuming unequal variances. All results shown are mean \pm SEM. c Bright field image from a TgCRND8 mouse show- ing cerebral blood vessels that are stained with Evans blue and shown from the boxed area at a higher magnification in the right panel. Counterstaining with thioflavin $\mathrm{S}$ of this section reveals co-localization of the amyloid within vessel walls. d Sections through the cerebral vasculature show immunohistochemical co-localization of CTR and RAMP3, components of the amylin receptor, on endothelial cells (identified with CD31 staining). e The CTR and RAMP3 are present on human microendothelial cells (HMEC-1). After exposure of HMEC- 1 cells to $\mathrm{A} \beta_{1-42}(0.5 \mu \mathrm{M})$ for $24 \mathrm{~h}$, there is an accumulation of amyloid on and in the vicinity of cells that are positive for CTR and RAMP3

soluble oligomeric A $\beta$. The mechanism(s) whereby these unique markers of amyloid pathology in AD are attenuated are not yet clear. It is possible that the driver of the age-dependent amyloid pathology is in some unknown ways linked to the activity of AMY/CTR since we have previously observed a parallel age-dependent increase in CTR and $A \beta$ in the hippocampal and cortical brain regions of transgenic AD mice [4]. A robust influence of altered AMY/CTR signaling upon A $\beta$-directed pathogenesis is supported by improvements in memory and pathology scored in two independent lines of APP695 transgenic mice that have both different genetic backgrounds and different tempos of AD-related changes [13, 14]. Moreover, a recent study revealed that amylin and its synthetic analog, pramlintide, when administered to AD mice, result 
in increased $\mathrm{A} \beta$ production via upregulation of APP and its processing enzyme, $\gamma$-secretase [17].

Additional explanations for a reduction in amyloid pathology likely involve roles for glia and the brain vasculature, both of which are invested with amylin receptors $[21,22]$. Since AMY/CTR complexes are localized on microglia, depletion of these target receptors for $\mathrm{A} \beta$ could attenuate the amyloid-induced neuroinflammation, including the cytokine release that is known to upregulate APP processing and thereby increase the rate of $\mathrm{A} \beta$ generation [23]. In the present study, we also identified a decrease in markers for activated microglia (and reactive astrocytes) in AMY/CTR depleted AD mice compared to AD mice. Thus, a reduction of a putative receptor target for $A \beta$ on microglia would be expected to result in diminished cytokine release and hence a reduction in APP processing. Indeed, we also observed a reduction in the APP processing enzyme, BACE1, in HETCTR depleted 5XFAD mice compared to 5XFAD mice. These findings would be also consistent with our previous pharmacological data showing that applications of antagonists of the amylin receptor can attenuate release of cytokines IL- $1 \beta$ and TNF- $\alpha$ in vitro and in the brains of AD mice and a reduction in $\mathrm{A} \beta$ production [21].

The amyloid deposition in cerebral vasculature constitutes one leg of a "three-legged stool" for pathologic change, with neuronal/synaptic compromise and neuroinflammation being the other two [21]. The demonstrated presence of the AMY/CTR in brain vasculature, in addition to that on neurons/synapses and microglia, suggests that it may also play a notable role in pathogenesis. In previous work, glial AMY/ CTR receptors have been shown to promote $A \beta$ influx into cells and subsequent formation of amyloid plaques [24]. In the vasculature, AMY/CTR receptors are localized on endothelial cells and thus may play a role in amyloid deposition in cerebral vessels. In this study, we observed a significant reduction in amyloid plaque numbers, size, and intensity in the brain vasculature of HetCTR + TgCRND8 mice compared to TgCRND8 mice. Experimentally, application of fluorescently labeled A $\beta$ on cultures of HMEC (endothelial) cells resulted in accumulation of amyloid within and over the cells in a plaque-like manner. Collectively, these observations suggest that activity of AMY/CTR receptors located on endothelial cells of the brain vasculature likely promotes amyloid deposition into vessel walls. Conversely, the reduction of this activity due to receptor depletion in HetCTR + TgCRND8 compound mice reduces amyloid deposition and associated AD pathology at these sites.

\section{Modulation of the AMY/CTR Axis and Clinical Interventions}

Amylin (IAPP) is being increasingly viewed as a "second amyloid" with its identification in AD brains and particularly those AD patients with a history of diabetes mellitus $[25,26]$. However, we did not observe any overt systemic effects of AMY/CTR reduction in either HetCTR or HetCTR $+5 \mathrm{xFAD}$ compound Tg mice; body weight and blood glucose levels did not change in either of the two strains of aged mice. Lack of these types of side effects is thus promising for adoption of a pharmacological approach aimed at tackling the serious pathological consequences of the two types of amyloid, namely, beta amyloid and amylin.

In summary, using a combination of electrophysiological, behavioral, and anatomical approaches, the results of this study provide evidence that genetic depletion of AMY/ CTR receptors in AD mouse models improves hippocampal synaptic plasticity and spatial memory, which is associated with a significant reduction in certain characteristic brain markers that are indicative of AD pathology. From a clinical perspective, the amylin receptor thus represents an attractive target for $\mathrm{AD}$ with the potential to improve cognition without substantial adverse effects of this therapeutic strategy.

Supplementary Information The online version contains supplementary material available at https://doi.org/10.1007/s12035-021-02490-y.

Acknowledgements The authors thank Dr. Khem Jhamandas (Queens University, Kingston, Ontario) for comments on the manuscript and the funding agencies.

Author Contribution AP, RK, WF, DM, and RS conducted the experiments and data analysis; RM, JZ, DM, DM, and JM provided and/or bred the transgenic mice; JHJ conceived the experiments and with AP wrote the first draft. RM, WF, RS, RD, and DW contributed to writing the manuscript.

Funding This research was supported by grants from the Canadian Institutes of Health Research (PS 159746), Alberta Innovates (Alberta Prion Research Institute), the Alzheimer's Society of Alberta and Northwest Territories, and the University Hospital Foundation (to JHJ) and JSPS KAKENHI grant number JP19K07014 (to RK).

Data and Materials Availability All data generated or analyzed during this study are included in this published article [and its supplementary information files].

Code Availability Not applicable.

\section{Declarations}

Ethics Approval All experiments were conducted in compliance with the guidelines set by the Canadian Council for Animal Care and with the approval of the Human Research Ethics Board and Animal Care Use Committee (Biomedical Sciences) at the University of Alberta (Protocol AUP00000268).

Consent to Participate Not applicable.

Consent for Publication Not applicable.

Conflict of Interest The authors declare competing interests. 
Open Access This article is licensed under a Creative Commons Attribution 4.0 International License, which permits use, sharing, adaptation, distribution and reproduction in any medium or format, as long as you give appropriate credit to the original author(s) and the source, provide a link to the Creative Commons licence, and indicate if changes were made. The images or other third party material in this article are included in the article's Creative Commons licence, unless indicated otherwise in a credit line to the material. If material is not included in the article's Creative Commons licence and your intended use is not permitted by statutory regulation or exceeds the permitted use, you will need to obtain permission directly from the copyright holder. To view a copy of this licence, visit http://creativecommons.org/licenses/by/4.0/.

\section{References}

1. Gallardo G, Holtzman DM (2019) Amyloid- $\beta$ and Tau at the crossroads of Alzheimer's disease. Adv Exp Med Biol 1184:187203. https://doi.org/10.1007/978-981-32-9358-8_16

2. Hardy J (2017) The discovery of Alzheimer-causing mutations in the APP gene and the formulation of the "amyloid cascade hypothesis.” FEBS J 284(7):1040-1044. https://doi.org/10.1111/ febs. 14004

3. Walsh DM, Selkoe DJ (2020) Amyloid $\beta$-protein and beyond: the path forward in Alzheimer's disease. Curr Opin Neurobiol 61:116-124. https://doi.org/10.1016/j.conb.2020.02.003

4. Jhamandas JH, Li Z, Westaway D, Yang J, Jassar S, MacTavish D (2011) Actions of $\beta$-amyloid protein on human neurons are expressed through the amylin receptor. Am J Pathol 178:140-149

5. Kimura R, MacTavish D, Yang J, Westaway D, Jhamandas JH (2012) Beta amyloid-induced depression of hippocampal longterm potentiation is mediated through the amylin receptor. J Neurosci 32(48):17401-17406. https://doi.org/10.1523/JNEUROSCI. 3028-12.2012

6. Soudy R, Patel A, Fu W, Kaur K, MacTavish D, Westaway D, Davey R, Zajac J et al (2016) Cyclic AC253, a novel amylin receptor antagonist, improves cognitive deficits in a mouse model of Alzheimer's disease. Alzheimers Dement (NY) 3(1):44-56. https://doi.org/10.1016/j.trci.2016.11.005

7. Fu W, Patel A, Kimura R, Soudy R, Jhamandas JH (2017) Amylin receptor: a potential therapeutic target for Alzheimer's disease. Trends Mol Med 23(8):709-720. https://doi.org/10.1016/j.molmed.2017.06.003

8. Adler BL, Yarchoan M, Hwang HM, Louneva N, Blair JA, Palm R, Smith MA, Lee HG et al (2014) Neuroprotective effects of the amylin analogue pramlintide on Alzheimer's disease pathogenesis and cognition. Neurobiol Aging 35(4):793-801. https://doi.org/10. 1016/j.neurobiolaging.2013.10.076

9. Zhu H, Wang X, Wallack M, Li H, Carreras I, Dedeoglu A (2015) Intraperitoneal injection of the pancreatic peptide amylin potently reduces behavioral impairment and brain amyloid pathology in murine models of Alzheimer's disease. Mol Psychiatry 20:252-262

10. Hay DL, Christopoulos G, Christopoulos A, Poyner DR, Sexton PM (2005) Pharmacological discrimination of calcitonin receptor: receptor activity-modifying protein complexes. Mol Pharmacol 67:1655-1665

11. Hay DL, Chen S, Lutz TA, Parkes DG, Roth JD (2015) Amylin: pharmacology, physiology, and clinical potential. Pharmacol Rev 67:564-600

12. Davey RA, Turner AG, McManus JF, Chiu WS, Tjahyono F, Moore AJ (2008) Calcitonin receptor plays a physiological role to protect against hypercalcemia in mice. J Bone Miner Res 23:1182-1193
13. Chishti MA et al (2001) Early-onset amyloid deposition and cognitive deficits in transgenic mice expressing a double mutant form of amyloid precursor protein. J Biol Chem 276:21562-21570

14. Oakley H, Cole SL, Logan S, Maus E, Shao P, Craft J, GuillozetBongaarts A, Ohno M et al (2006) Intraneuronal beta-amyloid aggregates, neurodegeneration, and neuron loss in transgenic mice with five familial Alzheimer's disease mutations: potential factors in amyloid plaque formation. J Neurosci 26(40):10129-10140. https://doi.org/10.1523/JNEUROSCI.1202-06.2006

15. Dahlgren KN, Manelli AM, Stine WB Jr, Baker LK, Krafft GA, LaDu MJ (2002) Oligomeric and fibrillar species of amyloidbeta peptides differentially affect neuronal viability. J Biol Chem 277:32046-32053

16. Zhu XX, Wang E, Wallack M, Na H, Hooker JM, Kowall N, Tao Q, Stein TD et al (2017) Amylin receptor ligands reduce the pathological cascade of Alzheimer's disease. Neuropharmacology 119:170-181. https://doi.org/10.1016/j.neuropharm2017.03.030

17. Mousa YM, Abdallah IM, Hwang M, Martin DR, Kaddoumi A (2020) Amylin and pramlintide modulate $\gamma$-secretase level and APP processing in lipid rafts [published correction appears in Sci Rep. 2020 Jul;10(1):11096]. Sci Rep 10(1):3751. https://doi.org/ 10.1038/s41598-020-60664-5

18. Kimura R, Devi L, Ohno M (2010) Partial reduction of BACE1 improves synaptic plasticity, recent and remote memories in Alzheimer's disease transgenic mice. J Neurochem 113(1):248-261. https://doi.org/10.1111/j.1471-4159.2010.06608.x

19. Kachooei E, Moosavi-Movahedi AA, Khodagholi F, Mozaffarian F, Sadeghi P, Hadi-Alijanvand H, Ghasemi A, Saboury AA et al (2014) Inhibition study on insulin fibrillation and cytotoxicity by paclitaxel. J Biochem 155(6):361-373. https://doi.org/10.1093/jb/ mvu012

20. Soudy R, Kimura R, Patel A, Fu W, Kaur K, Westaway D, Yang J, Jhamandas J (2019) Short amylin receptor antagonist peptides improve memory deficits in Alzheimer's disease mouse model. Sci Rep 9(1):10942. https://doi.org/10.1038/s41598-019-47255-9

21. Fu W, Vukojevic V, Patel A, Soudy R, MacTavish D, Westaway D, Kaur K, Goncharuk V et al (2017) Role of microglial amylin receptors in mediating beta amyloid (A $\beta)$-induced inflammation. J Neuroinflammation 14(1):199

22. Wang E, Zhu H, Wang X, Gower AC, Wallack M, Blusztajn JK, Kowall N, Qiu WQ (2017) Amylin treatment reduces neuroinflammation and ameliorates abnormal patterns of gene expression in the cerebral cortex of an Alzheimer's disease mouse model. J Alzheimers Dis 56(1):47-61. https://doi.org/10.3233/JAD-160677

23. Blasko I, Marx F, Steiner E, Hartmann T, Grubeck-Loebenstein B (1999) TNF alpha plus IFN gamma induce the production of Alzheimer beta-amyloid peptides and decrease the secretion of APPs. FASEB J 13(1):63-68. https://doi.org/10.1096/fasebj.13.1.63

24. Fu W, Shi D, Westaway D, Jhamandas JH (2015) Bioenergetic mechanisms in astrocytes may contribute to amyloid plaque deposition and toxicity. J Biol Chem 290(20):12504-12513. https://doi. org/10.1074/jbc.M114.618157

25. Jackson K, Barisone GA, Diaz E, Jin LW, DeCarli C, Despa F (2013) Amylin deposition in the brain: a second amyloid in Alzheimer disease? Ann Neurol 74:517-526

26. Martinez-Valbuena I, Valenti-Azcarate R, Amat-Villegas I, Riverol M, Marcilla I, de Andrea CE, Sánchez-Arias JA, Del Mar C-A et al (2019) Amylin as a potential link between type 2 diabetes and Alzheimer disease. Ann Neurol 86(4):539-551. https://doi. org/10.1002/ana. 25570

Publisher's Note Springer Nature remains neutral with regard to jurisdictional claims in published maps and institutional affiliations. 


\section{University Library}

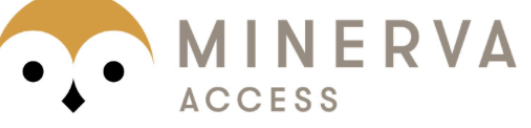

A gateway to Melbourne's research publications

Minerva Access is the Institutional Repository of The University of Melbourne

Author/s:

Patel, A;Kimura, R;Fu, W;Soudy, R;MacTavish, D;Westaway, D;Yang, J;Davey, RA;Zajac, JD; Jhamandas, JH

Title:

Genetic Depletion of Amylin/Calcitonin Receptors Improves Memory and Learning in Transgenic Alzheimer's Disease Mouse Models

Date:

2021-07-27

Citation:

Patel, A., Kimura, R., Fu, W., Soudy, R., MacTavish, D., Westaway, D., Yang, J., Davey, R. A., Zajac, J. D. \& Jhamandas, J. H. (2021). Genetic Depletion of Amylin/Calcitonin Receptors Improves Memory and Learning in Transgenic Alzheimer's Disease Mouse Models. MOLECULAR NEUROBIOLOGY, 58 (10), pp.5369-5382. https://doi.org/10.1007/ s12035-021-02490-y.

Persistent Link:

http://hdl.handle.net/11343/289467

License:

CC BY 